\title{
Dirhodium(II) Caprolactamate: An Exceptional Catalyst for Allylic Oxidation
}

Arthur J. Catino, Raymond E. Forslund, and Michael P. Doyle

Department of Chemistry and Biochemistry

The University of Maryland

College Park, MD 20742

\section{Supporting Information}

(4 pages) 
General. All reagents were commercially obtained unless otherwise noted and were purified according to the guidelines of Armarego and Chai. ${ }^{1}$ Olefins were distilled immediately prior to use. Yields reported are for isolated yields unless otherwise noted. All products were fully characterized and in agreement with those previously described. $^{2}$ tert-Butyl hydroperoxide (TBHP) was purchased from Aldrich as a 5.0-6.0 M solution in decane and stored over activated $3 \AA$ molecular sieves. The preparation of dirhodium(II) caprolactamate $\left[\mathrm{Rh}_{2}(\mathrm{cap})_{4} \cdot 2 \mathrm{CH}_{3} \mathrm{CN}\right]$ has been previously described. ${ }^{3} \mathrm{H}$ NMR (400 MHz) and ${ }^{13} \mathrm{C}$ NMR (100 MHz) spectra were obtained on a Bruker DRX-400 NMR as solutions in $\mathrm{CDCl}_{3}$. Chemical shifts are reported in parts per million (ppm, $\delta$ ) downfield from $\mathrm{Me}_{4} \mathrm{Si}$ (TMS); coupling constants are reported in Hertz (Hz). UV-Visible spectra were obtained on a Varian Cary 50 spectrophotometer using a xenon flash lamp. Preparative chromatographic purification was performed using SiliCycle (60A, 40-63 mesh) silica gel according to the method of Still. ${ }^{4}$ Thin layer chromatography (TLC) was performed on Merck $0.25 \mathrm{~mm}$ silica gel $60 \mathrm{~F}_{254}$ plates with visualization by fluorescence quenching or aqueous $\mathrm{KMnO}_{4}$ stain. Anhydrous $\mathrm{CH}_{2} \mathrm{Cl}_{2}$ was purified prior to use by nitrogen forced-flow over activated alumina as described. ${ }^{5}$

Procedure (0.1 mol\% catalyst): A $25 \mathrm{~mL}$ flask equipped with a stirbar was charged with olefin (2.72 mmol, 100 mol\%), $\mathrm{CH}_{2} \mathrm{Cl}_{2}(10 \mathrm{~mL}), \mathrm{K}_{2} \mathrm{CO}_{3}(1.36 \mathrm{mmol}, 50 \mathrm{~mol} \%)$, and $\mathrm{Rh}_{2}$ (cap) 4 (0.0027 mmol, $\left.0.1 \mathrm{~mol} \%\right)$. The flask was sealed with a septum allowing inclusion of air. An empty balloon was added to capture oxygen generated during the course of the reaction. To the mixture was added TBHP (13.6 mmol, 5 equiv) in one portion via syringe to which the color of the solution immediately turned from light blue to deep red. Oxygen generation was observed (filling the balloon). After 1 hour, the solution was filtered through a short plug of silica gel to remove the catalyst. Preparative column chromatography $\left(\mathrm{SiO}_{2}\right)$ yielded the analytically pure compound.

Procedure (1.0 mol\% catalyst): * A $5 \mathrm{~mL}$ flask equipped with a stirbar was charged with olefin $(0.272 \mathrm{mmol}, 100$ mol\%), $\mathrm{CH}_{2} \mathrm{Cl}_{2}(1 \mathrm{~mL}), \mathrm{K}_{2} \mathrm{CO}_{3}(0.136 \mathrm{mmol}, 50 \mathrm{~mol} \%)$, and $\mathrm{Rh}_{2}(\mathrm{cap})_{4}(0.00136 \mathrm{mmol}, 0.5 \mathrm{~mol} \%)$. The flask was fitted with a reflux condenser and heated to $40^{\circ} \mathrm{C}$ (oil bath) allowing inclusion of air. An empty balloon was added to the condenser to capture oxygen generated during the course of the reaction. To the mixture was added TBHP (1.36 mmol, 5.0 equiv) in one portion via syringe to which the color of the solution immediately turned from light blue to deep red. Oxygen generation was observed (filling the balloon). After 1.5 hours, a second portion of $\mathrm{Rh}_{2}$ (cap) 4 ( $\left.0.00136 \mathrm{mmol}, 0.5 \mathrm{~mol} \%\right)$ was added followed by a second portion of TBHP (1.36 mmol, 5.0 equiv). After stirring for another 1.5 hours, the solution was filtered through a short plug of silica gel to remove the catalyst. Preparative column chromatography $\left(\mathrm{SiO}_{2}\right)$ yielded the analytically pure compound.

Procedure (1 gram preparation of 3-methyl-2-cyclohexene-1-one): A $100 \mathrm{~mL}$ flask equipped with a stirbar was charged with 1-methylcyclohexene (1.00 g, $10.4 \mathrm{mmol}, 100 \mathrm{~mol} \%), \mathrm{CH}_{2} \mathrm{Cl}_{2}$ (40 mL), $\mathrm{K}_{2} \mathrm{CO}_{3}$ (720. mg, $5.20 \mathrm{mmol}$, $50 \mathrm{~mol} \%$ ), and $\mathrm{Rh}_{2}$ (cap) $)_{4}(8.0 \mathrm{mg}, 0.01 \mathrm{mmol}, 0.1 \mathrm{~mol} \%)$. The flask was sealed with a septum allowing inclusion of air. An empty balloon was added to capture oxygen generated during the course of the reaction. To the mixture was added TBHP (10.4 mL, $52.0 \mathrm{mmol}, 5$ equiv) in one portion via syringe to which the color of the solution immediately turned from light blue to deep red. Oxygen generation was observed (filling the balloon). After 20 minutes, the solution was filtered though a short plug of silica gel to remove the catalyst. The solvent was removed via rotary evaporation at $0{ }^{\circ} \mathrm{C}$. Preparative column chromatography $\left(\mathrm{SiO}_{2}, 3: 1\right.$ hexanes/ $\left.\mathrm{Et}_{2} \mathrm{O}\right)$ yielded $1.02 \mathrm{~g}(89 \%)$ 3-methyl-2-cyclohexene-1-one: ${ }^{1} \mathrm{H}$ NMR (400 MHz, $\left.\mathrm{CDCl}_{3}\right) \delta 5.88$ (s, 1H), 2.36-2.27 (m, 4H), 2.03-1.96 (m, 5H); ${ }^{13} \mathrm{C}$ NMR $\left(100 \mathrm{MHz}, \mathrm{CDCl}_{3}\right) \delta$ 199.2, 162.4, 126.3, 36.7, 30.6, 24.1, 22.3; IR (KBr) $1670 \mathrm{~cm}^{-1}$; TLC $\mathrm{R}_{f}=0.16(3: 1$ hexanes/Et $2 \mathrm{O})$; HRMS (EI) calcd for $\mathrm{C}_{7} \mathrm{H}_{10} \mathrm{O} 110.0732$, found $110.0733(\mathrm{M}+)$.

\footnotetext{
${ }^{1}$ Armarego, W. L. F.; Chai, C. L. L. Purification of Laboratory Chemicals; $5^{\text {th }}$ ed., Elsevier Science: New York, 2003.

2 (a) Yu, J.-Q.; Corey, E. J. Org. Lett. 2002, 4, 2727. (b) Yu, J.-Q.; Corey, E. J. J. Am. Chem. Soc. 2003, 125, 3232.

${ }^{3}$ Doyle, M. P.; Westrum, L. J.; Wolthuis, W. N. E.; See, M. M.; Boone, W. P.; Bagheri, V.; Pearson, M. M. J. Am. Chem. Soc. 1993, 115, 958.

${ }^{4}$ Still, W. C.; Kahn, M.; Mitra, A. J. J. Org. Chem. 1978, 43, 2923.

${ }^{5}$ Pangborn, A. B.; Giardello, M. A.; Grubbs, R. H.; Rosen, R. K.; Timmers, F. J. Organometallics 1996, 15, 1518.

${ }^{*}$ This procedure was followed for the allylic oxidation of 2-cycloheptene-1-one (Table 1, entry 10) and

2-cyclopenten-1-one ethylene ketal (Table 1, entry 11). The allylic oxidation of 1-nitro-cyclohexene (Table 1, entry 5) was conducted using the same procedure but at room temperature for $24 \mathrm{hrs}$.
} 
Table 1S. Yield as a Function of Solvent in the Allylic Oxidation of 1-Acetylcylcohexene Catalyzed by $\mathrm{Rh}_{2}(\text { cap })_{4}$

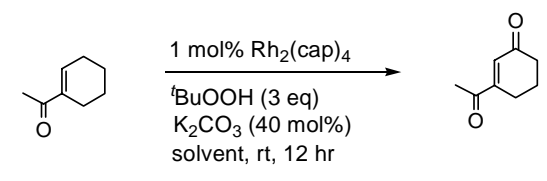

\begin{tabular}{ccc}
\hline Entry & Solvent $^{a}$ & Yield (\%) \\
\hline 1 & $\mathrm{CHCl}_{3}$ & 41 \\
2 & $\mathrm{C}_{6} \mathrm{H}_{6}$ & 17 \\
3 & toluene & 29 \\
4 & $\mathrm{Et}_{2} \mathrm{O}$ & No reaction \\
5 & $\mathrm{THF}$ & No reaction \\
6 & hexane & 29 \\
7 & $\mathrm{EtOAc}$ & 57 \\
8 & $\mathrm{CH}_{3} \mathrm{CN}$ & No reaction \\
9 & neat & 34 \\
10 & $\mathrm{CH}_{2} \mathrm{Cl} l_{2}$ & 65 \\
${ }^{a}$ Solvent concentration was $0.27 \mathrm{M}$ [substrate] for all entries.
\end{tabular}

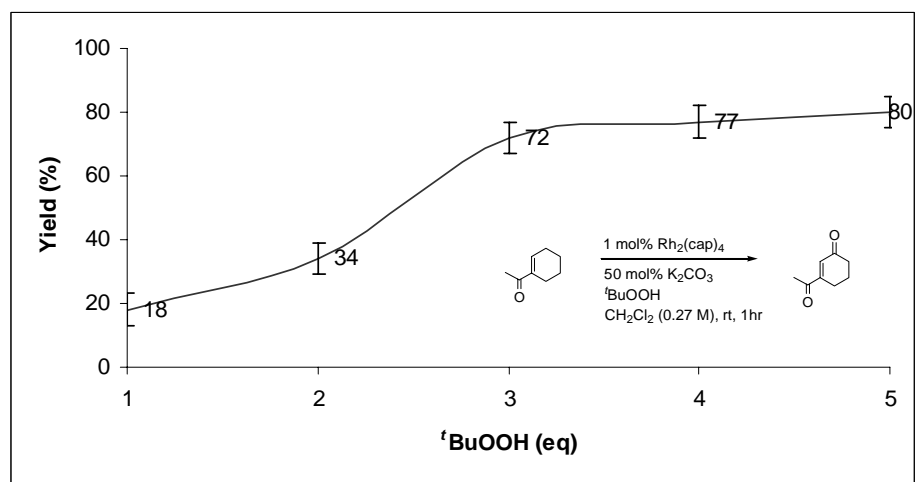

Figure 1S. Product Yield as Function of the Equivalents of TBHP for the Allylic Oxidation of 1-Acetylcyclohexene Catalyzed by $\mathrm{Rh}_{2}(\text { cap })_{4}$

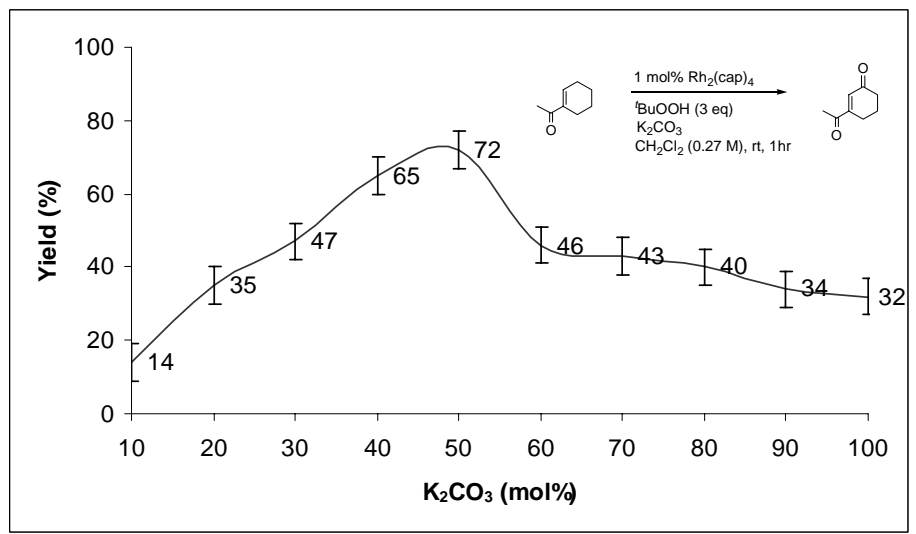

Figure 2S. Product Yield as a Function of the Amount of $\mathrm{K}_{2} \mathrm{CO}_{3}$ for the Allylic Oxidation of 1-Acetylcyclohexene Catalyzed by $\mathrm{Rh}_{2}(\mathrm{cap})_{4}$ 


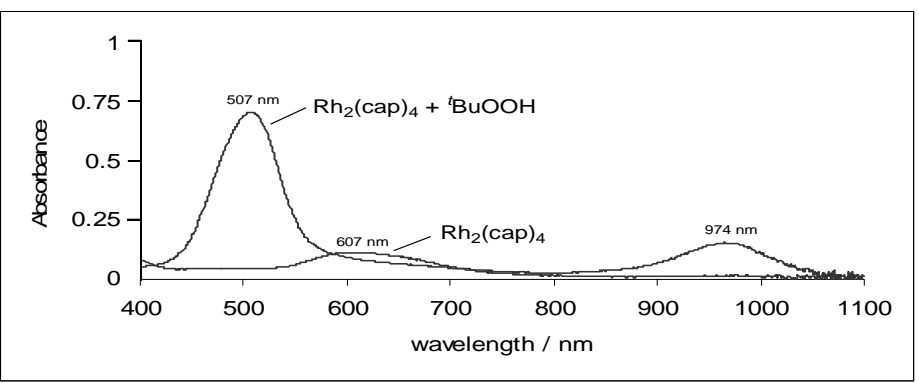

Figure 3S. UV-visible spectrum of $\mathrm{Rh}_{2}(\text { cap })_{4}\left(9.05 \times 10^{-4} \mathrm{M}\right.$ in $\left.\mathrm{CH}_{2} \mathrm{Cl}_{2}\right)$ upon addition of TBHP

Scheme 1S. Evidence for the Intermediacy of tert-Butyl Peroxy Ethers in the Allylic Oxidation of 1-Phenylcyclohexene Catalyzed by $\mathrm{Rh}_{2}(\text { cap })_{4}$
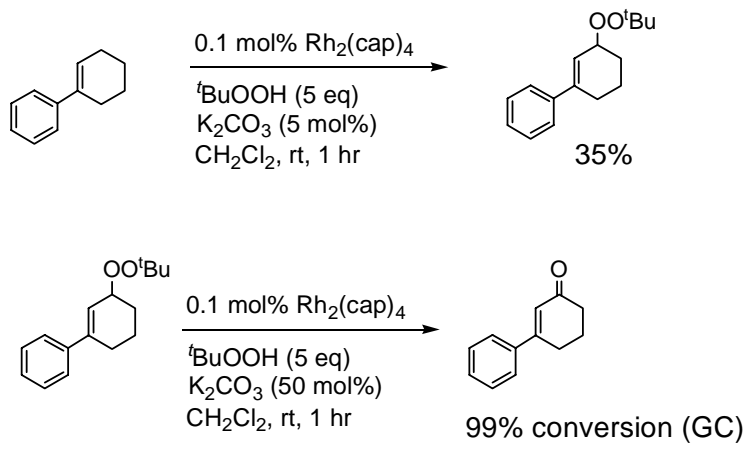

Scheme 2S. Measured Oxygen Generation for the Allylic Oxidation of 1-Acetylcyclohexene by $\mathrm{Rh}_{2}(\operatorname{cap})_{4}$

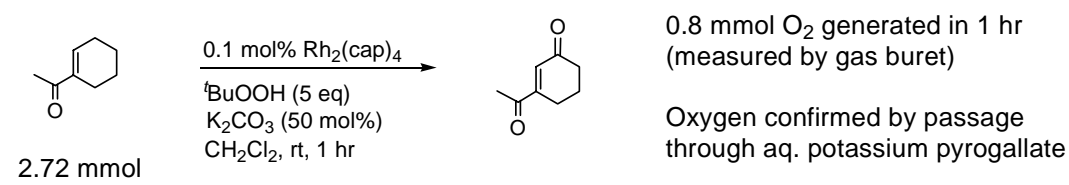

Scheme 3S. Allylic Oxidation of 1-Acetylcyclohexene Catalyzed by $\left[\mathrm{Rh}_{2}{ }^{5+}\right]$

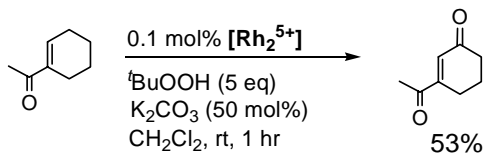

$\left[\mathbf{R h}_{2}{ }^{5+}\right.$ ]: To a solution of $\mathrm{Rh}_{2}(\mathrm{cap})_{4}(23.0 \mathrm{mg}, 0.031 \mathrm{mmol})$ in $\mathrm{CH}_{2} \mathrm{Cl}_{2}(10 \mathrm{~mL})$ open to air was added TBHP $(0.625 \mathrm{~mL}, 3.12 \mathrm{mmol})$. The solution immediately turned from light blue to deep red (oxygen evolution was observed). After 1 hour, the solution was evaporated to dryness leaving a deep red glass-like solid. Column chromotagraphy $\left(\mathrm{SiO}_{2}\right)$ using 8:1 DCM/MeOH eluded a red band that was collected and evaporated. The solid was placed under high vacuum ( 0.1 Torr) for 24 hours. The resultant red solid was submitted to the reaction above yielding the enedione product in $53 \%$ yield. 